
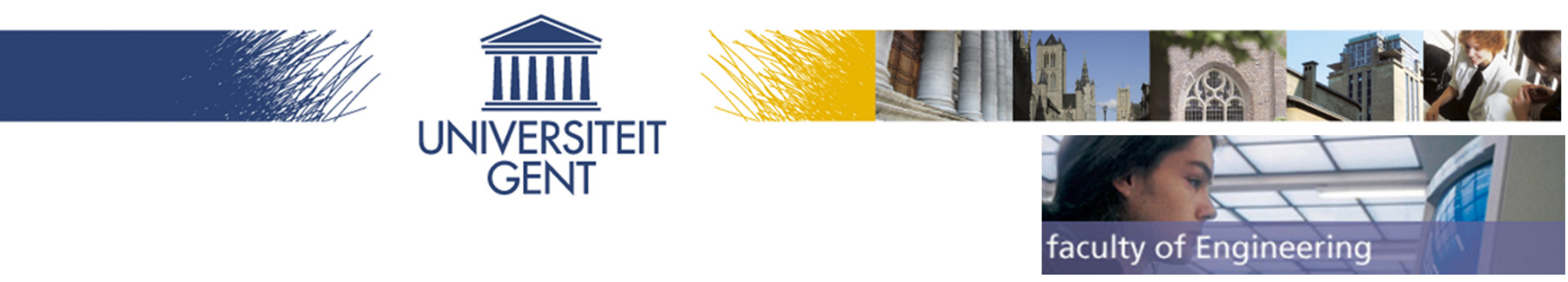

\title{
Effect of strain rate on the forming behaviour of sheet metals
}

\author{
Patricia Verleysen and Jan Peirs
}

Department of Materials Science and Engineering, Ghent University, Belgium

Faculty of Engineering and Architecture - Department of Materials Science and Engineering 


\section{DC06 1mm}

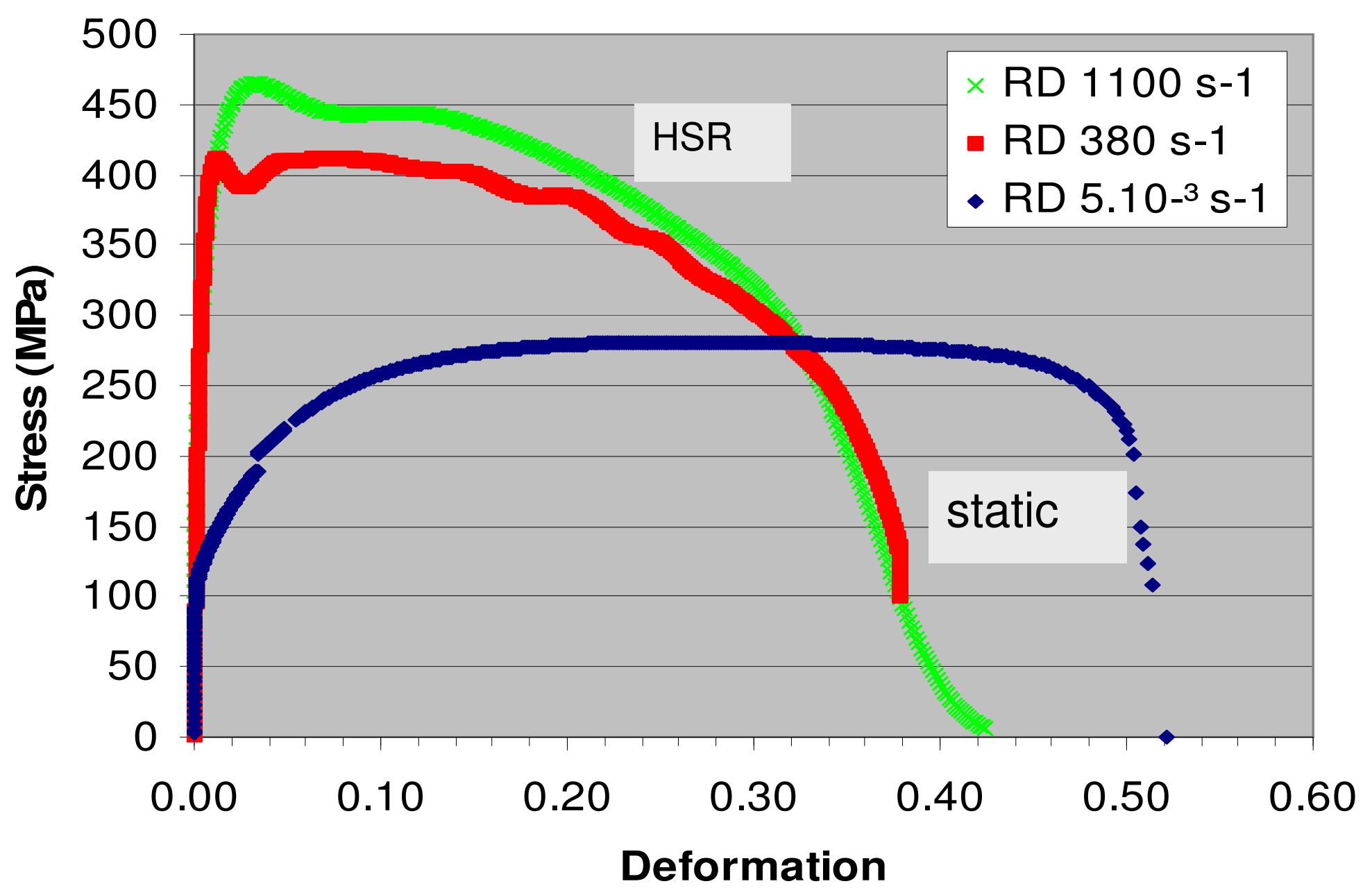




\section{Processes and materials of interest}

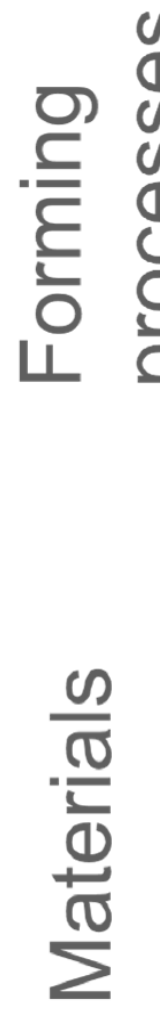

- Electromagnetic pulse forming, hydroforming Strain rates upto $3500 / \mathrm{s}$

- Deepdrawing, roll forming, bending

Locally strain rates upto 100/s

- DC04 (EN 10027-1)

$\frac{\frac{\infty}{\pi}}{\frac{\pi}{\frac{\pi}{0}}}$ unalloyed deep-drawing steel used for body components in cars

- CMnAI TRIP

laboratory made

multiphase

austenite transforms to martensite during plastic straining 


\section{Overview}

- Experiments

- Modelling of high strain rate behaviour

- Calculation of high strain rate FLD

- Conclusions 


\section{Overview}

- Experiments

- Modelling of high strain rate behaviour

- Calculation of high strain rate FLD

- Conclusions 


\section{Split Hopkinson tensile bar experiments}

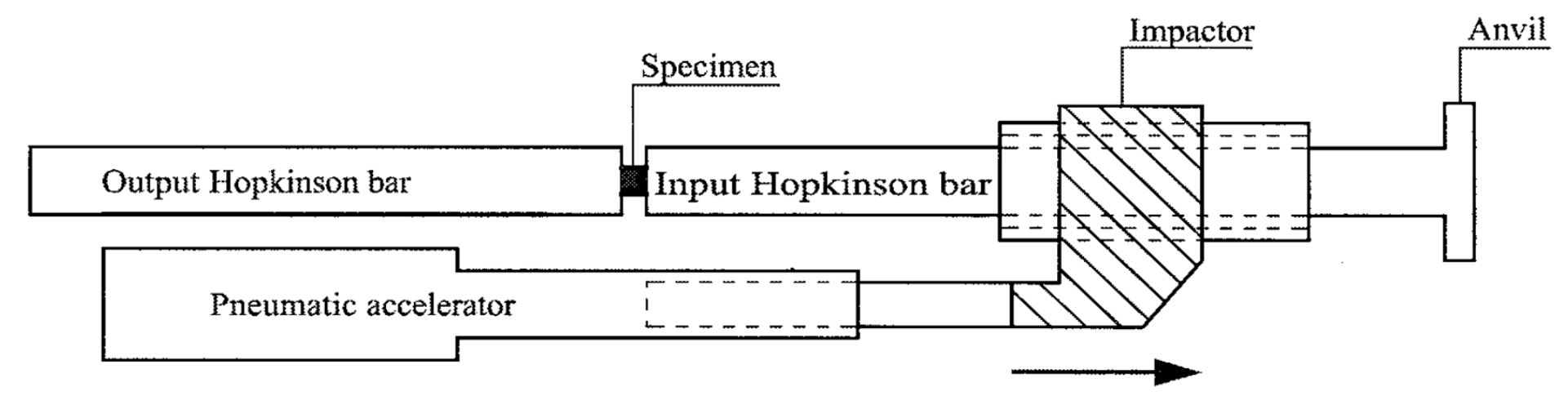

\section{Loading wave}

length $\Rightarrow$ loading duration

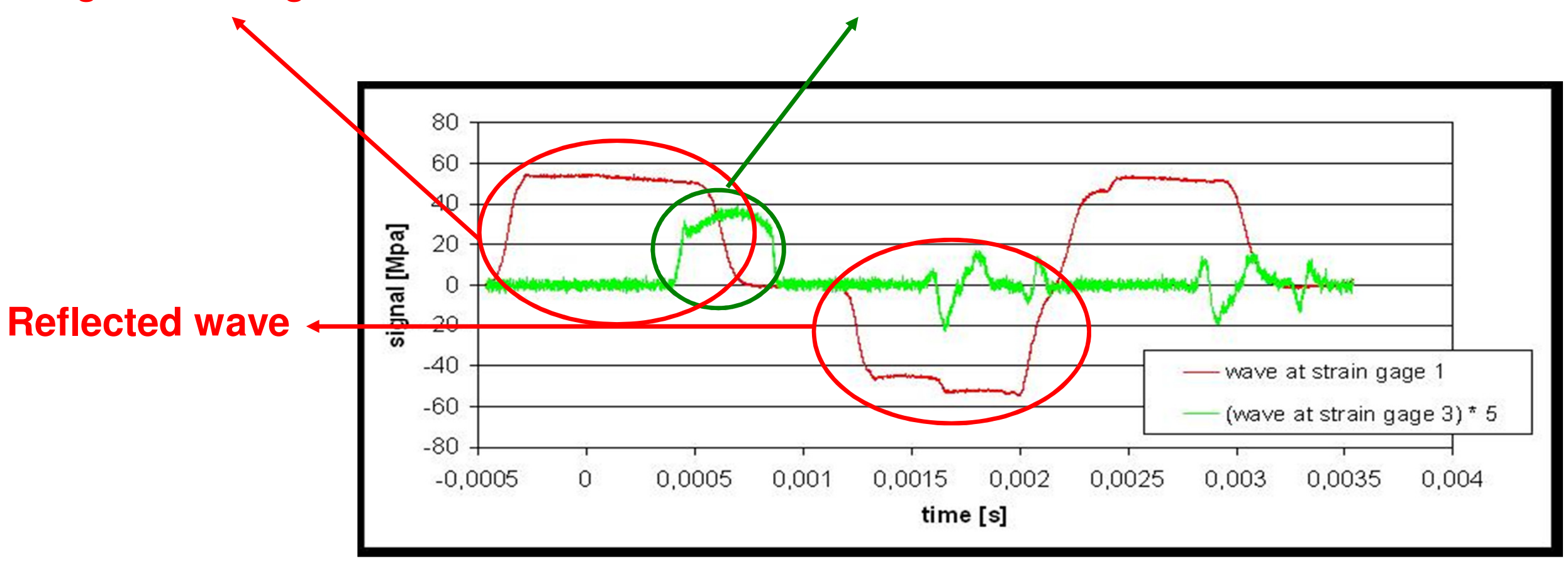




\section{Split Hopkinson tensile bar experiments}

Setup at Ghent University

- Uniaxial tensile load

- Adjustable strain rate up to $\sim 2000 \mathrm{~s}^{-1}$

- Loading time up to $1.2 \mathrm{~ms}$

- Specimen glued between bars
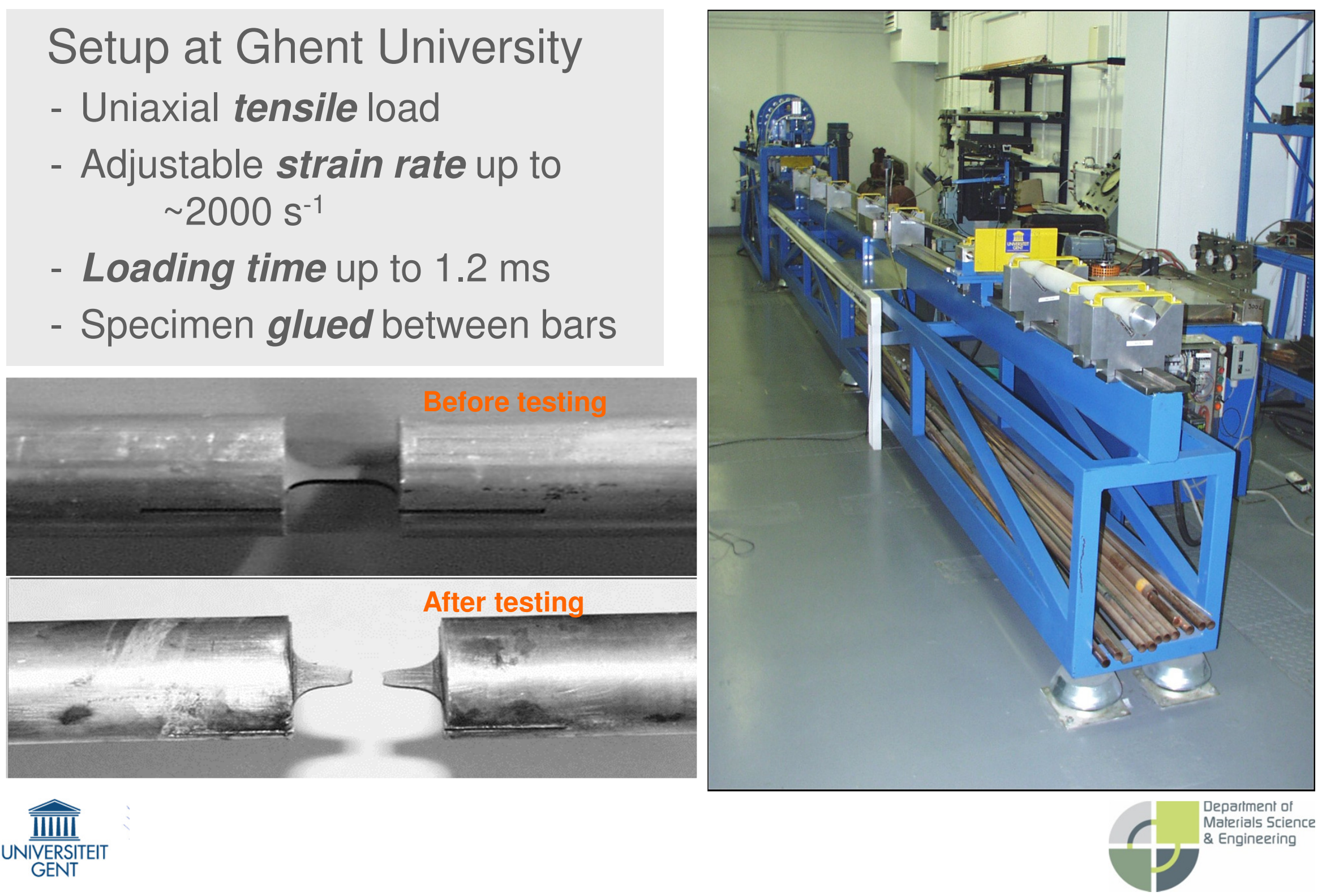


\section{Test results}

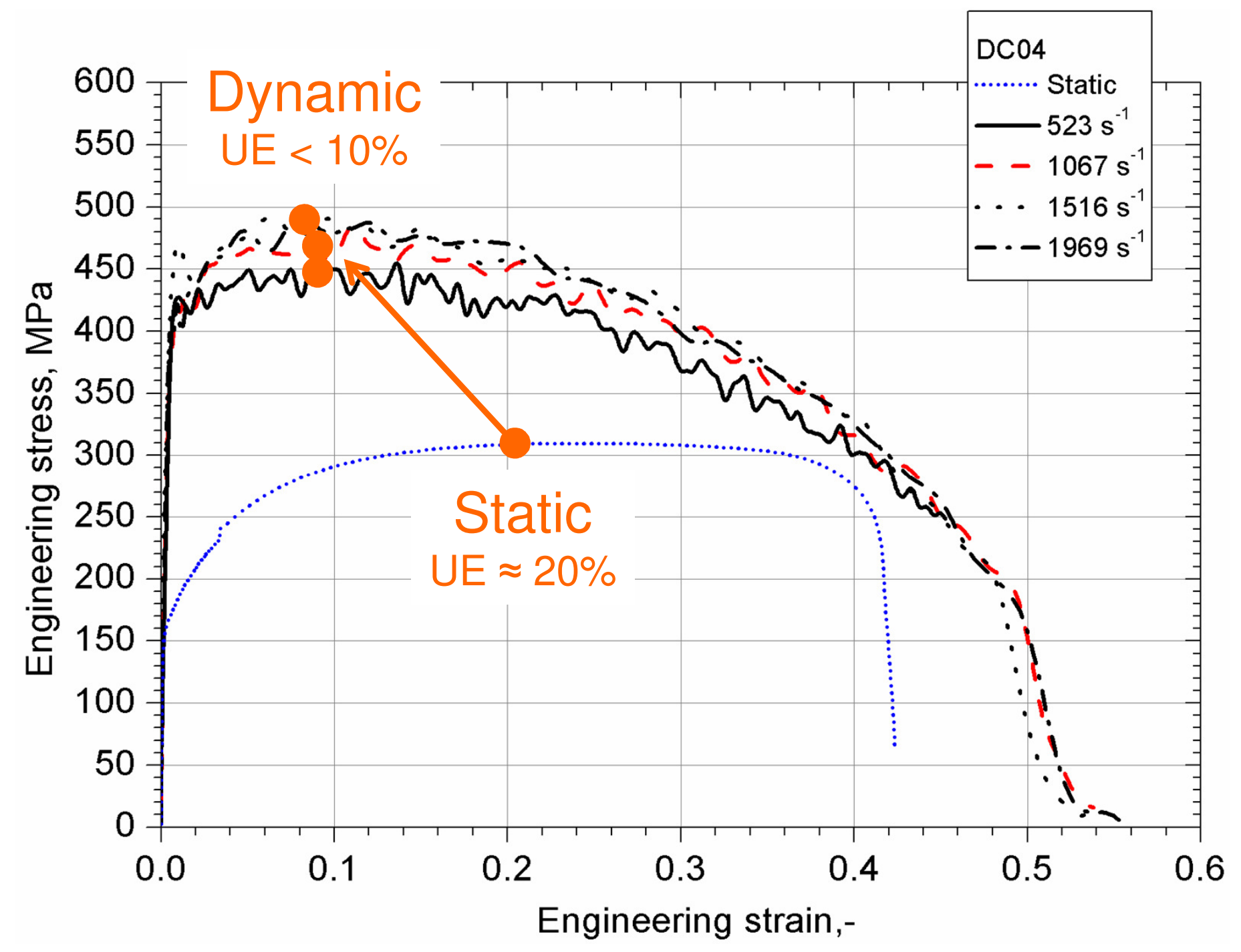




\section{Test results}

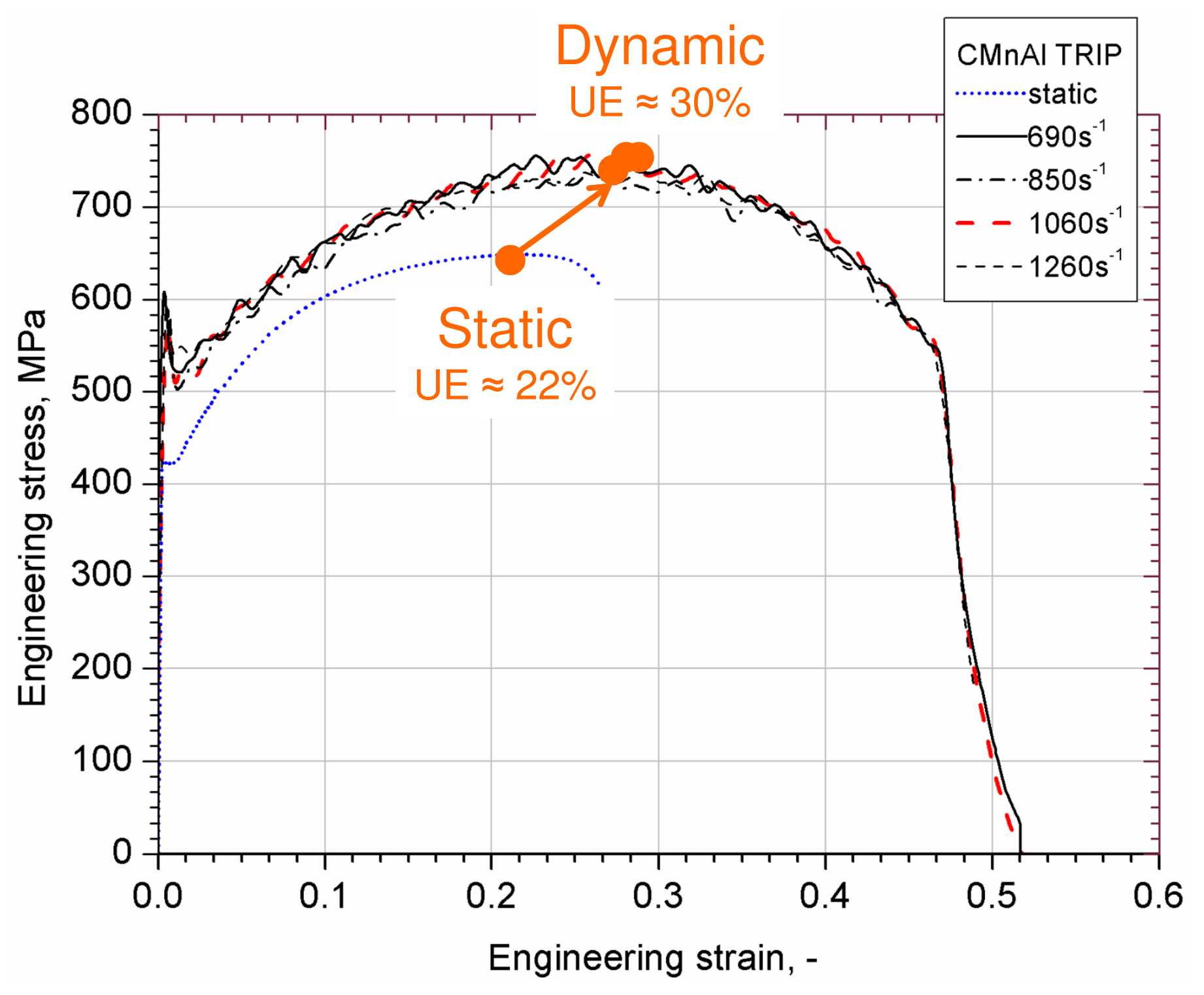




\section{Overview}

\section{- Experiments}

- Modelling of high strain rate behaviour

- Calculation of high strain rate FLD

- Conclusions 


\section{Phenomenological modeling}

\section{Johnson-Cook}

- Strain rate dependent hardening

- Temperature dependent softening

$$
\sigma=\left(\mathrm{A}+\mathrm{B} \varepsilon^{\mathrm{n}}\right)\left(1+C \ln \frac{\dot{\varepsilon}}{\dot{\varepsilon}_{0}}\right)\left(1-\left[\frac{T-T_{\text {room }}}{T_{\text {melt }}-T_{\text {room }}}\right]^{m}\right)
$$

adiabatic heating

$$
\Delta T=\frac{\beta}{\rho c} \int \sigma d \varepsilon_{p}
$$

\section{Voce}

- Strain rate dependence and adiabatic conditions accounted for by the use of strain rate dependent parameters

$$
\sigma=\sigma_{0}+K\left(1-e^{-n \varepsilon_{p}}\right)
$$




\section{Modelling}

DC04

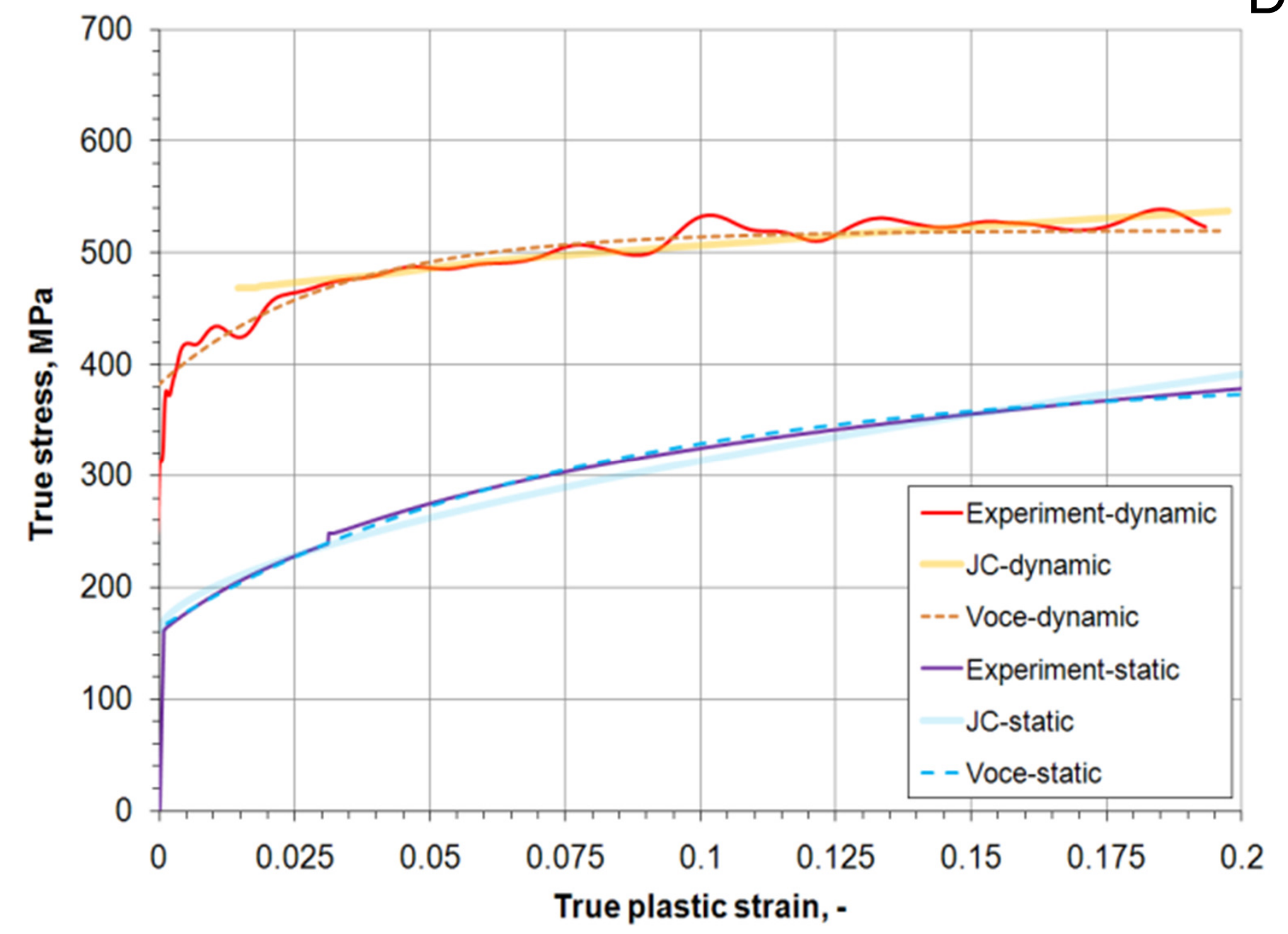




\section{Modelling}

TRIP

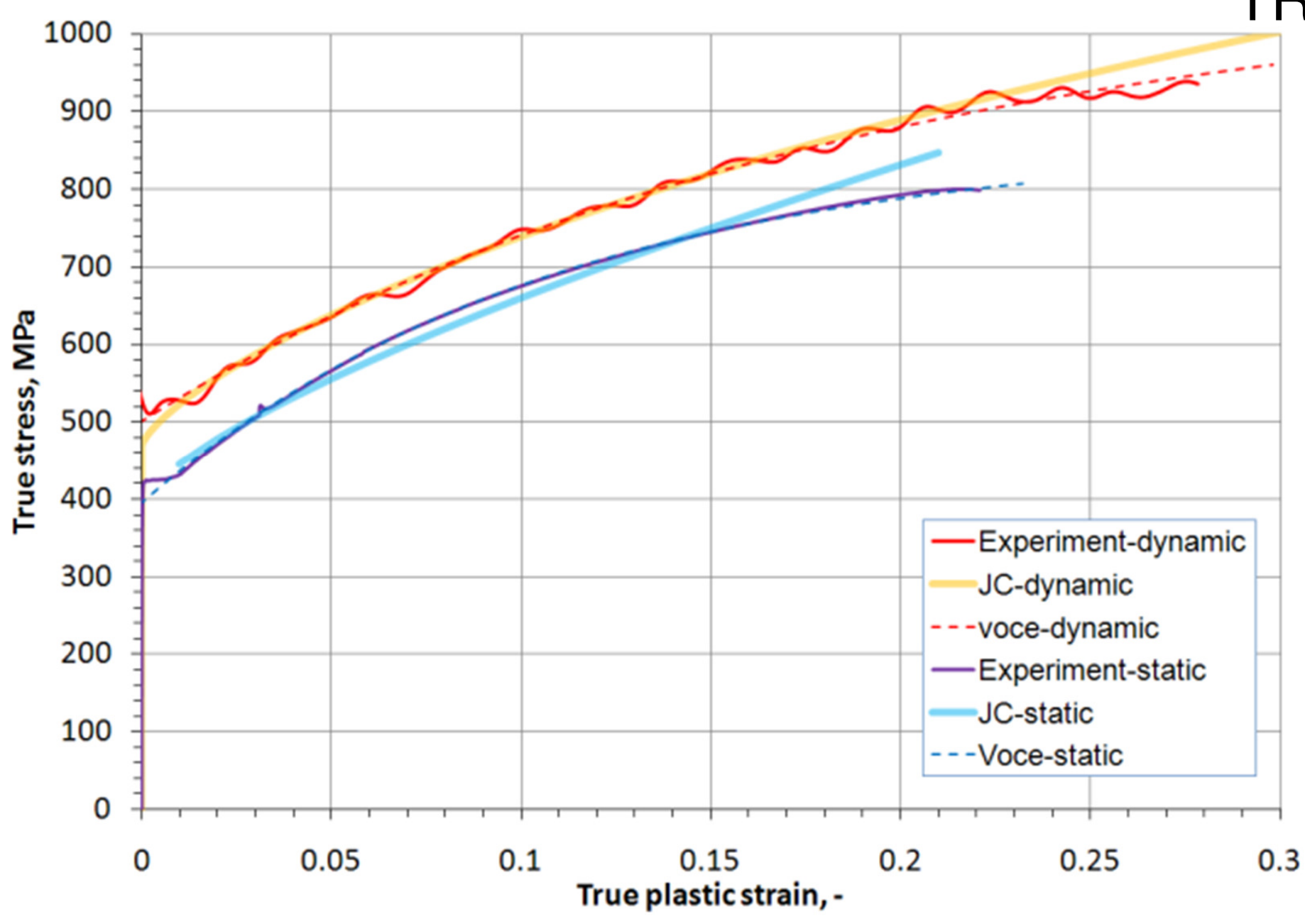




\section{Overview}

- Experiments

- Modelling of high strain rate behaviour

- Calculation of high strain rate FLD

- Conclusions 


\section{Calculation of high strain rate FLD}

- Marciniak-Kuczynski model

initial imperfection in sheet metal modelled by band of smaller thickness

during biaxial straining imperfection zone deforms more than uniform zone

when strain localizes, difference increases drastically

failure of sheet 


\section{Calculation of high strain rate FLD}

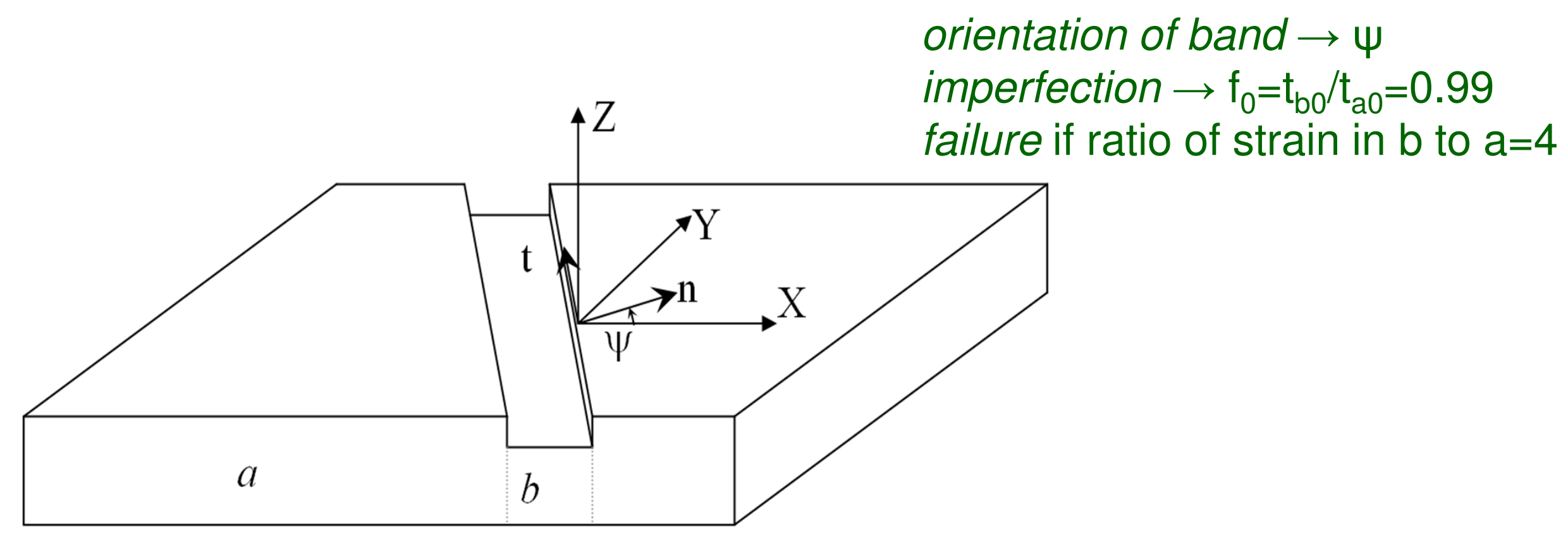

For a certain predefined biaxial strain state critical strain calculated for all $\psi$ angles Lowest strain value is THE critical strain 


\section{Calculation of high strain rate FLD}

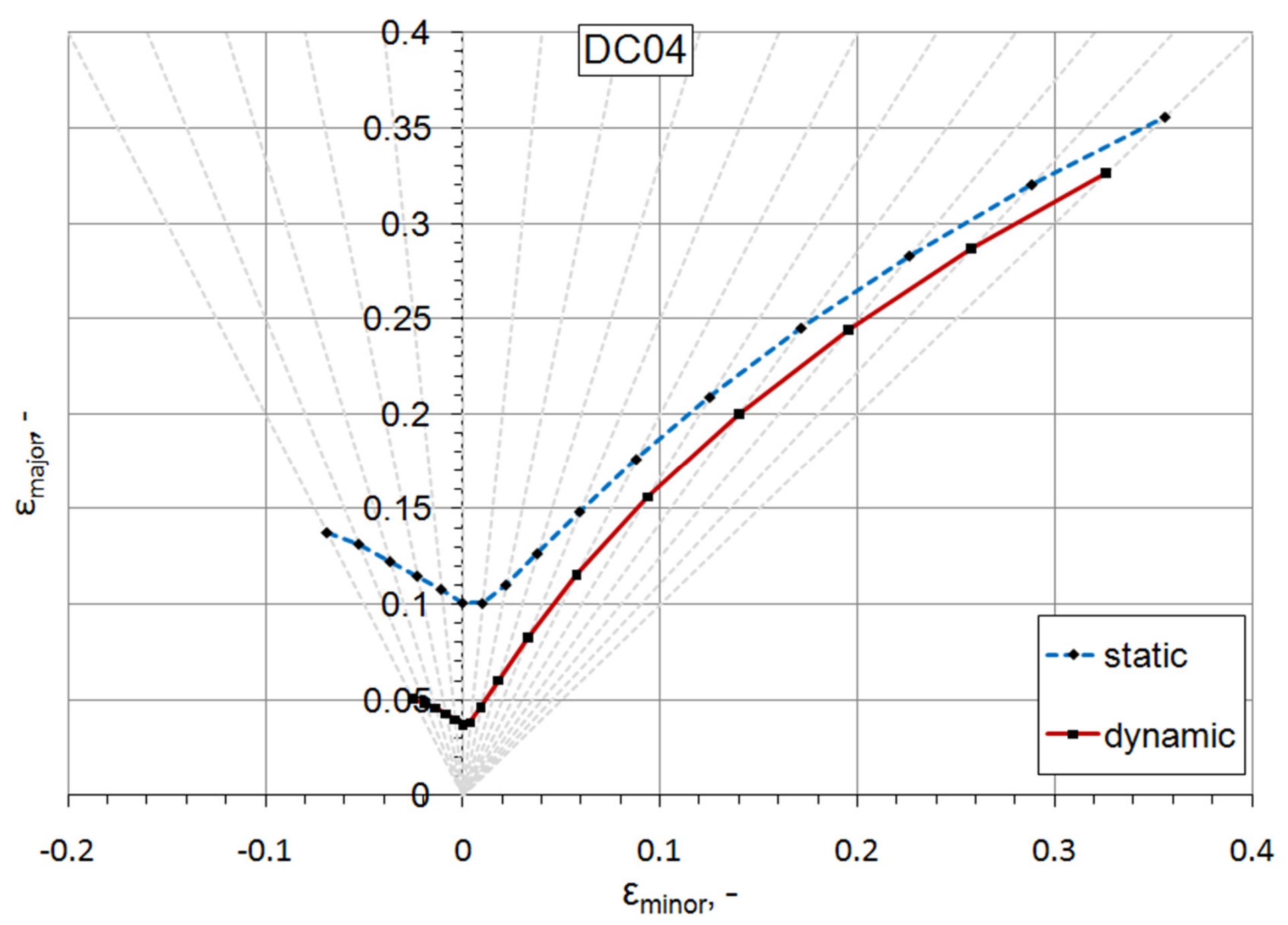




\section{Calculation of high strain rate FLD}

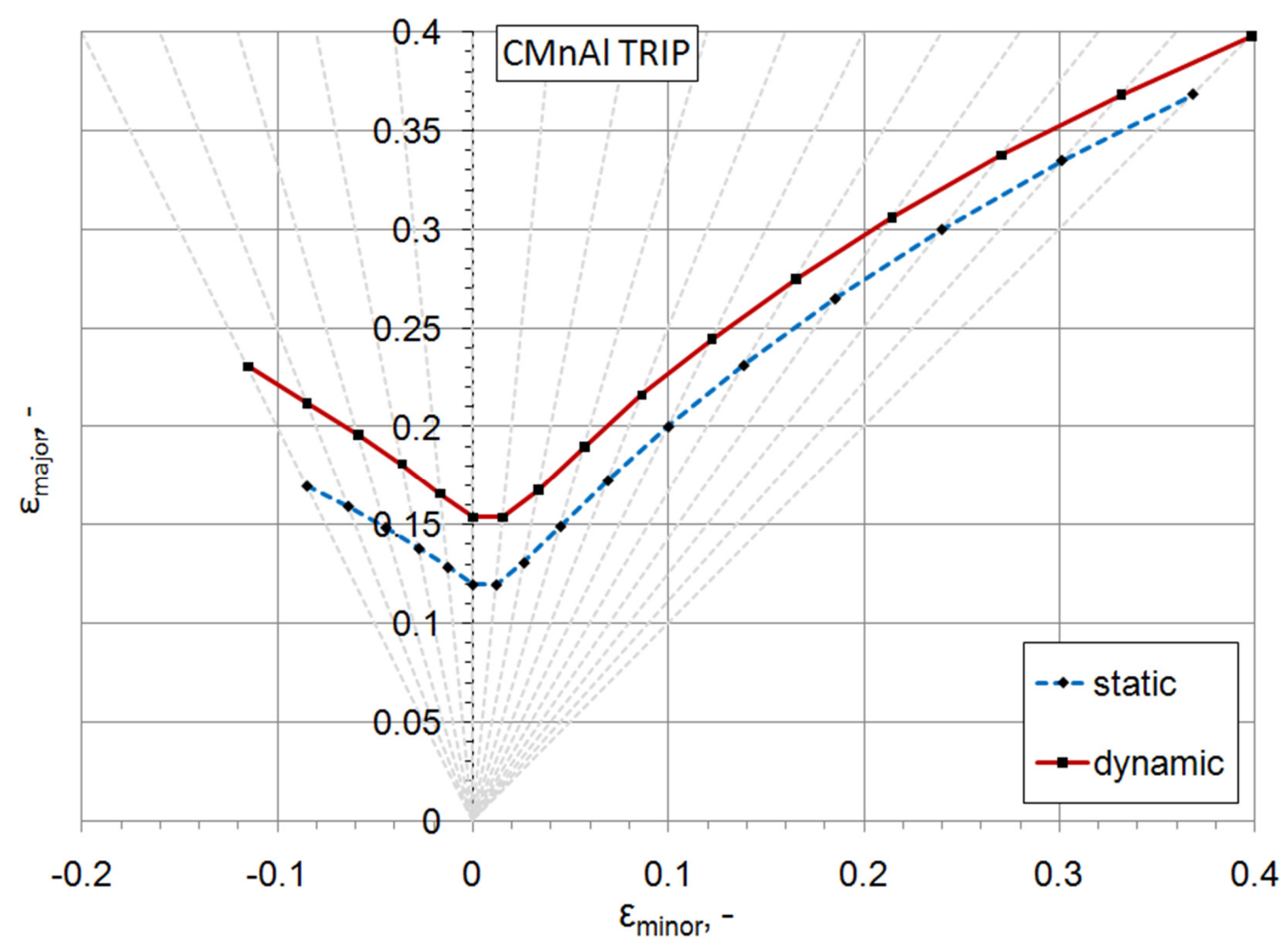




\section{Overview}

- Experiments

- Modelling of high strain rate behaviour

- Calculation of high strain rate FLD

- Conclusions 


\section{Conclusions}

- Influence of strain rate on forming properties of DC04 and a CMnAI TRIP steel is studied

High strain rate tensile experiments are carried out

Johnson-Cook and Voce model parameters determined Experimental results are used to calculate FLDs

based on Marciniak-Kuczynski model

- Forming limit diagrams show a non-negligible effect of the strain rate

DC04 FLD shifts downwards with increasing strain rate TRIP FLD enhances considerably if the strain rate is increased 


\section{Remarks}

- Anisotropy not taken into account in FLDs

Limitation due to implementation, not inherent to $\mathrm{M}-\mathrm{K}$ model

- now Hill implemented

- Post-necking behaviour not taken into account

Better results obtained with shear tests instead of tensile tests 


\section{Questions ??}

More information:

Verleysen, P; Peirs, J; Van Slycken, J; Faes, K and Duchene, L (2011): Effect of strain rate on the forming behaviour of sheet metals. Journal of materials processing technology nr. 8, Vol. 211, 1457-1464

Department of Materials Science and Engineering Mechanics of Materials and Structures

Ghent University, Belgium

Patricia.Verleysen@UGent.be 